\title{
Mefloquine Long Half-Life is Associated with Sustained Psychiatric Side Effects: A Case Report
}

\author{
Eric Constant ${ }^{1 *}$, Emmanuel Hermans ${ }^{2}$, Pierre Wallemacq ${ }^{3}$ and Arnaud Capron ${ }^{4}$ \\ ${ }^{1}$ Department of Adult Psychiatry, Clinique Universities St Luc, Institute of Neurosciences, Catholic University of Leuven, Belgium \\ ${ }^{2}$ Institute of Neurosciences, Group of Neuropharmacology, Catholic University of Leuven, Belgium \\ ${ }^{3}$ Department of Clinical Chemistry, Clinique Universities St Luc, Catholic University of Leuven, Belgium \\ ${ }^{4}$ Clinical and Forensic Toxicology, Clinique Universities St Luc, Catholic University of Leuven, Belgium
}

*Corresponding author: Eric Constant, Head of Adult Psychiatric Department, Clinique Universities St Luc, Institute of Neurosciences, Catholic University of Leuven, Belgium, Tel: +3227642160; E-mail: Eric.Constant@uclouvain.be

Received date: January 08, 2018; Accepted date: January 18, 2018; Published date: January 28, 2018

Copyright: (C) 2018 Constant $\mathrm{E}$, et al. This is an open-access article distributed under the terms of the Creative Commons Attribution License, which permits unrestricted use, distribution, and reproduction in any medium, provided the original author and source are credited.

Citation: Constant E, Hermans E, Wallemacq P, Capron A (2018) Mefloquine Long Half-Life is Associated with Sustained Psychiatric Side Effects: A Case Report. J Neuropsychiatry Vol. 2 No. 1:2.

\section{Abstract}

Background: Psychiatric side effects of mefloquine, an antimalarial drug, are well known (agitation, depression and suicidal ideation, psychosis with paranoia and hallucinations).

Case Presentation: We report the case of a 30-year-old man without psychiatric antecedents, who developed acute psychosis and depression with suicidal ideation after five weeks of treatment with mefloquine. The symptomatology decreased rapidly a few days later, under antipsychotic drug (olanzapine) and benzodiazepines (lorazepam) and the treatment doses were diminished after one week. However, three weeks later, the same symptomatology reappeared and the treatment doses of both psychotropic drugs had to be increased once again. The antidepressant escitalopram was also introduced. Three months were necessary to definitively suppress the psychotropic drugs. Plasma mefloquine clearance was monitored by a validated liquid-chromatography massspectrometric method and confirmed the very long halflife of the drug, which is estimated at 14.5 days.

Conclusions: The pathophysiological mechanisms of these psychiatric side effects probably involve a toxic limbic encephalopathy. Mefloquine is highly lipophilic and may accumulate in the limbic system. In conclusion, due to the very long half-life of mefloquine, psychiatric symptoms can persist for weeks, necessitating an appropriate psychotropic treatment. Chronic symptoms resulting from permanent neurotoxicity may also occur.

Keywords: Mefloquine; Side effects; Half-life; Psychosis; Paranoia; Suicide

\section{Case Report}

\section{Background}

Mefloquine is a 4-quinolinemthanol antimalarial drug, well documented for its psychiatric side effects, including nervousness, agitation, and sleep disorders with nightmares, depression and frank psychosis with paranoia or hallucinations [1]. Other reports of suicidal ideation, suicide and acts of violence [2] have raised safety concerns. However, numerous questions remain unresolved so far: Delay for appearance and duration of mefloquine psychiatric symptoms? Recommended duration of the psychotropic treatment? Estimation of mefloquine elimination half-life?

\section{Case presentation}

A 30-year-old man without psychiatric antecedents had been five weeks under mefloquine $(250 \mathrm{mg} /$ week) for malaria prophylaxis for a business trip in Africa, when he started developing emotional lability, insomnia, nightmares, followed a few days later by anorexia, acute psychosis with paranoid delusions, magical thinking, restlessness and agitation. He had a depressed mood with suicidal ideations. Obsessions toward dangerous objects (knifes) and morbid ideas about death were also present. The patient had no familial or personal antecedents and no other risk factors for psychosis: there was no familial history of psychosis or bipolar disorder, and no exposure to viruses, toxins or malnutrition while in the womb. He had a normal social life and was engaged in a stable sentimental relationship and did not use drugs. After his repatriation from Africa, he was hospitalized in our psychiatric department. Since his physical examination and laboratory analyses (full blood screening, thyroid function, toxicology/ drugs of abuse) were normal, mefloquine was considered responsible for these symptoms. A close surveillance of the patient was organized, given the active suicidal ideations and 
requests for euthanasia. The patient was treated with olanzapine $(20 \mathrm{mg} / \mathrm{d})$ and lorazepam $(10 \mathrm{mg} / \mathrm{d})$. Five days after onset of this treatment, his clinical state rapidly improved: paranoid delusions and suicidality were reduced, and there was a progressive return to a better sleep. Nightmares were less present. One week later, he was discharged with olanzapine $(10 \mathrm{mg} / \mathrm{d})$ and lorazepam $(5 \mathrm{mg} / \mathrm{d})$. Given his favorable evolution after three weeks, olanzapine and lorazepam were reduced to $2.5 \mathrm{mg} / \mathrm{d}$ for both drugs. Nevertheless, the paranoid delusions reappeared with depressed mood and suicidal ideations. The patient had to be re-hospitalized for one week and olanzapine and lorazepam were increased to $10 \mathrm{mg} / \mathrm{d}$ and $5 \mathrm{mg} / \mathrm{d}$, respectively. The antidepressant escitalopram $10 \mathrm{mg} / \mathrm{d}$ was introduced as well. Three months were necessary to gradually suppress the psychotropic drugs and to definitively stabilize his mental state.

Plasma mefloquine levels were monitored by a validated liquid-chromatography mass-spectrometric method. Briefly, blood was sampled on lithium heparin as an anticoagulant. In order to minimize mefloquine degradation, plasma was kept at $4^{\circ} \mathrm{C}$ for a maximum of $48 \mathrm{~h}$ before mefloquine testing. Drug was extracted from $200 \mu \mathrm{L}$ of plasma, at $\mathrm{pH}$ 9.2, with ethyl acetate. Organic layer was evaporated to dryness and dried extract was reconstituted with $100 \mu \mathrm{L}$ of acetonitrile and transferred into vials for LC-MS/MS analysis.

Plasma mefloquine clearance was of $611 \mathrm{ng} / \mathrm{ml}$ at $\mathrm{d} 5$ after the last intake of mefloquine, $183 \mathrm{ng} / \mathrm{mL}$ at d34 and $95 \mathrm{ng} / \mathrm{mL}$ at $d 43$. These data confirm the very long half-life of the drug, which is estimated at 14.5 days, with an extrapolated plasma concentration at $\mathrm{d} 0$ around $800 \mathrm{ng} / \mathrm{mL}$, falling within the standard range of concentrations in prophylactic treatment $(450-1100 \mathrm{ng} / \mathrm{mL})[3]$.

\section{Discussion}

The usual range and time course of psychiatric side effects upon mefloquine use are well documented: the prodromal phase usually takes place with personality change, anxiety, unease, phobias, a sense of impending doom and restlessness [4]. After a few days or weeks, a full psychotic phase develops with magical thinking, auditory or visual hallucinations, persecutory mania, aggression, panic attacks, confusion, and symptoms of depression and sometimes acts of violence and suicide. Terrifying nightmares, symptoms of derealization and depersonalization, compulsions toward dangerous objects and morbid curiosity about death are also frequently reported, which was the case in our patient. These symptoms are frequently dismissed as coincidental or attributed to recreational drug use or pre-existing mental illness [5]. The pathophysiological mechanisms probably involve a toxic limbic encephalopathy [6]. Mefloquine is highly lipophilic and may accumulate in the limbic system, inhibiting electric coupling of neurons with effects on limbic inhibition and mesolimbic dopaminergic tone [7], like ketamine and other hallucinogens. Its toxicity may progress to the frontal lobe (behavioral disinhibition) or involve the brainstem (nausea, emesis, vertigo, nystagmus, and photophobia).

\section{Conclusion}

In conclusion and contrary to what is generally admitted, psychiatric side effects can occur at any time during mefloquine use and not only after the first days of treatment [1]. Hence, a clinical case of psychotic and mood symptoms developing after six months of malaria prophylaxis with mefloquine have been reported [8]. Due to the very long halflife of the drug, psychiatric symptoms can persist for weeks, necessitating an appropriate psychotropic treatment. Moreover, some of the psychiatric symptoms can even persist months to years after mefloquine discontinuation [1]. The drug may cause chronic symptoms resulting from permanent neurotoxicity and neurodegeneration of limbic and brainstem centers [9]. Vertigo lasting as long as 18 months has been reported [10].

\section{Author's Contributions}

C.E. and H.E. were major contributors in writing the paper. W.P. and C.A. analyzed and interpreted the patient data regarding plasma mefloquine clearance. All authors read and approved the final manuscript.

\section{References}

1. FDA Drug Safety Communication (2013) FDA approves label changes for antimalarial drug mefloquine hydrochloride due to risk of serious psychiatric and nerve side effects.

2. Moore TJ, Glenmullen J, Furberg CD (2010) Prescription drugs associated with reports of violence towards others. PLoS One 5: 15337.

3. Bergqvist $Y$, Churchill FC, Mount DL (1988) Determination of mefloquine by electron-capture gas chromatography after phosgene derivatization in biological samples and in capillary blood collected on filter paper. J Chromatogr 428: 281-290.

4. Ritchie EC, Block J, Nevin RL (2013) Psychiatric side effects of mefloquine: applications to forensic psychiatry. J Am Acad Psychiatry Law 41: 224-235.

5. Schlagenhauf P, Steffen R (2000) Neuropsychiatric events and travel: do antimalarials play a role ? J Trav Med 7: 225-226.

6. Nevin RL (2011) Mefloquine neurotoxicity and gap junction blockade: critical insights in drug repositioning. Neurotoxicology 32: 986-987.

7. Steffensen SC, Bradley KD, Hansen DM, Wilcox JD, Wilcox RS, et al. (2011) The role of connexin-36 gap junctions in alcohol intoxication and consumption. Synapse 65: 695-707.

8. Oueriagli Nabih F, Touhami M, Laffinti A, Abilkacem L (2011) Mood disorder after malaria prophylaxis with mefloquine (two case reports). Encephale 5: 393-396.

9. Ebert U, Brandt C, Loscher W (2002) Delayed sclerosis, neuroptrotection and limbic epileptogenesis after status epilepticus in the rat. Epilepsia 43: 86-95.

10. Grupp D, Rauber A, Froscher W (1994) Neuropsychiatric disturbances after malaria prophlaxis with mefloquine (in German). AktNeurol 21: 134-136. 